\title{
Removal of Sulphides and Benzene in Fluid Catalytic Cracking Gasoline by Insitu Hydrogenation Over NbFAPSO-5
}

\author{
Nchare Mominou ${ }^{1, *}$, Lei Wang ${ }^{2}$, Badohok Sarki ${ }^{1}$ \\ ${ }^{1}$ Department of Mining Engineering, University of Ngaoundere, Ngaoundere, Cameroon \\ ${ }^{2}$ Shanghai Institute of Technology, Shanghai, China
}

Email address:

nmominou@yahoo.com (N. Mominou)

${ }^{*}$ Corresponding author

\section{To cite this article:}

Nchare Mominou, Lei Wang, Badohok Sarki. Removal of Sulphides and Benzene in Fluid Catalytic Cracking Gasoline by Insitu Hydrogenation Over NbFAPSO-5. American Journal of Applied Chemistry. Vol. 7, No. 2, 2019, pp. 59-63. doi: 10.11648/j.ajac.20190702.13

Received: March 15, 2019; Accepted: April 17, 2019; Published: May 23, 2019

\begin{abstract}
Niobium containing aluminophosphate molecular sieve (NbFAPSO-5) was hydrothermally synthesized with AlPO-5 type structure. Characterization of this catalyst was performed by X-ray diffraction to determine its structure, inductive coupled plasma-atomic emission spectrometry (ICP-AES) for its elemental composition and infrared spectrometry (IR) to access its acidic properties. X-ray diffraction patterns confirmed well AlPO-5 type structure. ICP-AES analysis confirmed the incorporation of silicon (12.9\%), aluminium (15.4\%), phosphorous (21.9\%), iron (5.62\%) and niobium (0.39\%) into AlPO-5 framework. Infrared spectrometry analysis showed that both Bronsted and Lewis sites were found in the synthesized sample. A fixed-bed reactor was used to investigate the activity of the resulting catalysts in the removal of sulfides and benzene in fluid catalytic cracking gasoline. Under suitable conditions of a metal loading of $15 \%$, a reaction temperature of $423 \mathrm{~K}$, a reaction time of $30 \mathrm{~min}$, a space velocity of $3 \mathrm{~h}^{-1}$, and a reaction pressure of $1 \mathrm{MPa}$; desulfurization and debenzolization ratios reach $100 \%$ and $19.9 \%$ respectively. Research octane number of the gasoline increased by two units. This remarkable behavior makes NbFAPSO-5 family, a potential candidate for industrial application as catalysts in the clean fuel.
\end{abstract}

Keywords: Niobium, NbFAPSO-5, Desulfurization, Debenzolization, Insitu Hydrogenation

\section{Introduction}

Due to air quality deterioration caused by consumption of fossil fuel, new regulations have been proposed to limit the content of aromatic compounds and sulfides in gasoline[14]. Sulfides produce sulfur dioxide after combustion under high temperature, which can contribute to acid rain and poison the catalytic converter used in automobiles. In general, refiners convert aromatic compounds into saturated naphthenic compounds through hydrogenation at first, and the second procedure is to hydrogenate the saturated naphthenic molecules into isoparaffinic compounds, which have the same carbon atoms as the original molecules but with more branches. The process includes ring contraction, and selective ring opening [5-9]. The removal of sulfides and benzene has been widely studied [10-15]. Efforts have been made in the study of aromatic and sulfide hydrogenation under mild conditions [16-19]. Simple aromatic hydrogenation into saturated hydrocarbons, e.g., naphthenes, would result in a decline in the research octane number (RON) of gasoline [20, 21]; the side reactions, e.g., cleavage, would produce hydrocarbons with low molecular weight, which not only decreases vehicle fuels yield [22], but also causes high Reid vapor pressure (RVP), which is strictly regulated to be under $0.05 \mathrm{MPa}$ for gasoline in most states. This poses a challenge to refiners, who need not only to sustain quality and properties of gasoline, but also to decrease the benzene and sulfur content. The challenge with catalyst design is that hydrogenation of benzene takes place in the process of deep desulfurization of gasoline. Therefore, the catalysts need to be highly active towards hydrogenation in the presence of heterocyclic sulfur compounds. In our previous work, simultaneous removal of sulfides and benzene in FCC gasoline was explored by in situ hydrogenation over 
$\mathrm{NiLaIn} / \mathrm{ZrO}_{2}-\mathrm{r}-\mathrm{Al}_{2} \mathrm{O}_{3}$, with emphasis on the influence of catalyst properties and operating conditions on activities [23].

In this paper we report the removal of sulfides and benzene in FFC gasoline over NbFAPSO-5molecular sieve catalyst.

\section{Experimental Procedures}

\subsection{Synthesis and Characterization of NbFAPSO-5 Molecular Sieve.}

Synthesis of NbFAPSO-5 follows the same procedure as described for FAPSO-5 [31, 32], except that niobium solution is added just after putting silicon source. X-ray powder diffraction data was obtained on a Rigaku D/max diffractometer using $\mathrm{Cu}$ ka radiation at $40 \mathrm{kv}$ and $60 \mathrm{Ma}$. Elemental composition of this catalyst was accessed using ICP-AES performed on IRIS 1000 and the acidity by mean of infrared spectrometry performed on Nicolet Magna-IR 550.

\subsection{Catalyst Tests}

The reaction apparatus setup is illustrated in Figure 1. Catalyst was activated at $673 \mathrm{~K}$ for 25 minutes under a nitrogen atmosphere. The reaction temperature set to 313 $600 \mathrm{~K}$. The raw material and methanol preheated to 313-600
$\mathrm{K}$ and introduced in the reactor. The product was cooled, separated by a gas-liquid separator, and then analyzed by gas chromatography-mass spectrometry.

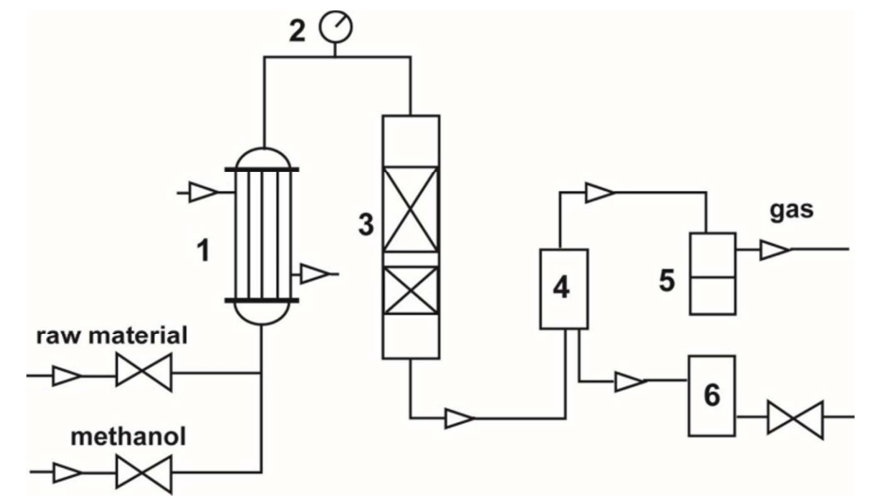

Figure 1. A scheme of the reaction setup for hydrogenation of sulfides and benzene (1. preheater, 2. pressure gauge, 3. hydrogenation reactor, 4. condenser, 5. tail gas processor, 6. product tank).

The desulfurization and debenzolization ratios were calculated as follow:

$$
\begin{gathered}
\text { Desulfurization ratio }=\left(1-\left(\frac{\text { Massof sulfides in refined gasoline }}{\text { Mass of sulfides in raw gasoline }}\right) \times 100 \%\right. \\
\text { Debenzolization ratio }=\left(1-\frac{\text { Mole of benzene in refined gasoline }}{\text { Mole of benzene in raw gasoline }}\right) \times 100
\end{gathered}
$$

\section{Results and Discussions}

\subsection{Catalyst Characterization}

The XRD pattern of NbFAPSO-5 is shown in Figure 2. Compositional analysis of the synthesized sample NbFAPSO-5 showed that $39 \%$ of niobium was confirmed to be incorporated while maintaining AIPO-5 type structure.

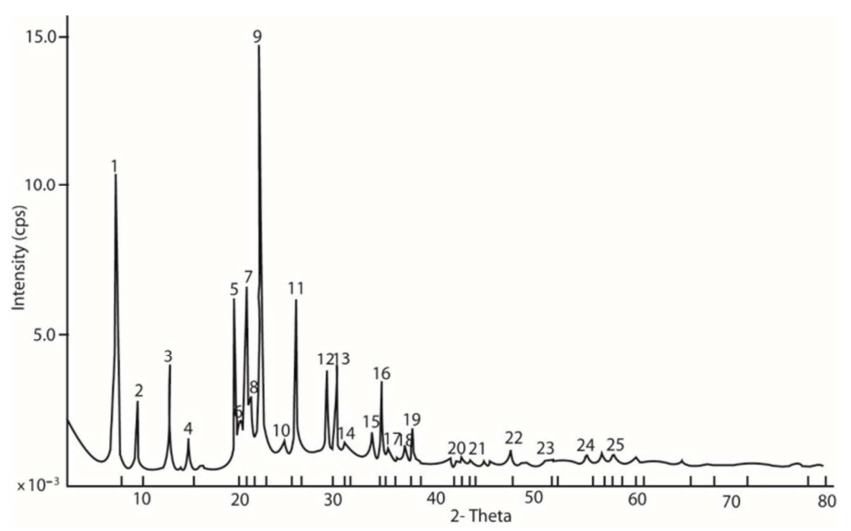

Figure 2. XRD patterns of niobium containing NbFAPSO-5.

The resulting infrared spectrum of pyridine chemisorption on NbFAPSO-5 is shown in Figure 3.

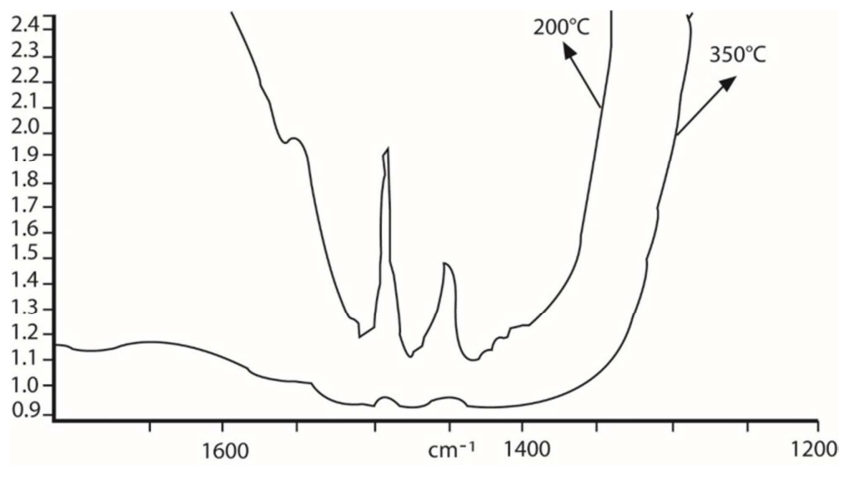

Figure 3. Infrared spectrum of NbFAPSO-5.

Treatment at $200^{\circ} \mathrm{C}$ shows an expressed peak at 1450 and light intensity peak at $1450 \mathrm{~cm}^{-1}$. Treatment at $350^{\circ} \mathrm{C}$ does not show peak at $1450 \mathrm{~cm}^{-1}$ meaning that in this catalyst, both strong and weak Lewis acid sites exist with strong Brönsted acid sites. Brönsted and Lewis acid are nearly at equilibrium; this behavior can promote both oxidation and esterification reactions.

\subsection{Effect of $\mathrm{Nb}$ Loading on Desulfurization and Debenzolization}

From figure 4, we can see that desulfurization ratio significantly increased, while debenzolization ratio displayed a gentle trend as a whole with the increase of the $\mathrm{Nb}$ loading in NbFAPSO-5. The desulfurization and debenzolization 
ratio reached $99 \%, 19.9 \%$, respectively, at the $\mathrm{Nb}$ loading of $15 \%$.

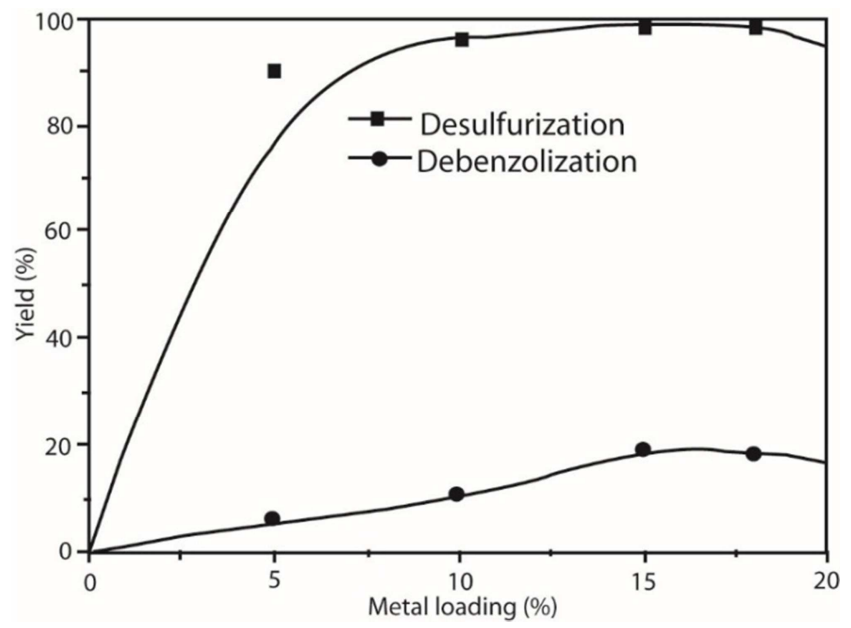

Figure 4. Effect of $\mathrm{Nb}$ loading on desulfurization and debenzolization.

\subsection{Effect of Reaction Temperature on Desulfurization and Debenzolization}

From figure 5 we can see that when the reaction temperature was increased from 313 to $423 \mathrm{~K}$, the desulfurization and debenzolization ratios, increased gradually with increasing temperature to rich $100 \%$ and $38.8 \%$ respectively.

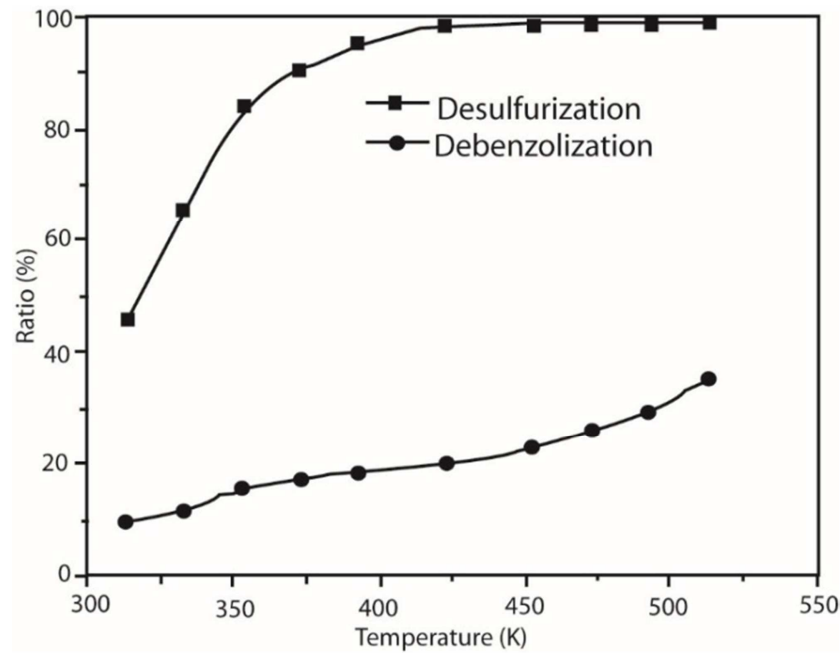

Figure 5. Effect of reaction temperature on desulfurization and debenzolization.

\subsection{Effect of Reaction Time on Desulfurization and Debenzolization}

Desulfurization and debenzolization ratio gradually increased as the reaction time was increased (Figure 6). With a reaction time of 40 minutes, $99 \%$ of desulfurization was performed and 22\%debenzolization completed. At 60 minutes of reaction, desulfurization and debenzolization of gasoline decreased significantly, meaning that a proper contact time of substances and catalyst was more needed.

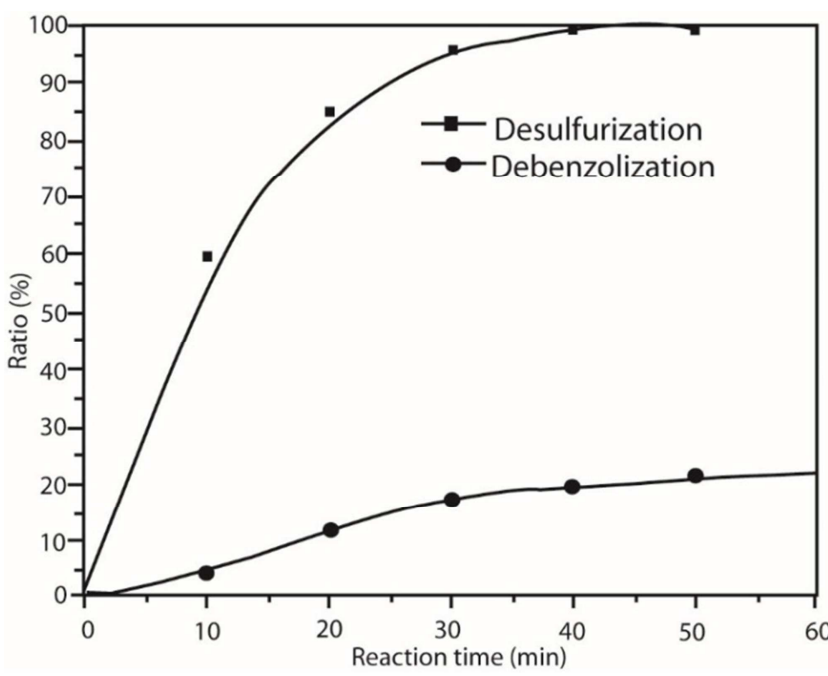

Figure 6. Effect of reaction time on desulfurization and debenzolization.

\subsection{Effect of Pressure on Desulfurization and Debenzolization}

Desulfurization and debenzolization were carried out over NbFAPSO-5 catalyst at the pressure from 0.4 to $1.4 \mathrm{MPa}$ (Figure 7). The desulfurization and debenzolization increased with increasing pressure, which indicates that pressure has significant effect on desulfurization and debenzolization activity. Debenzolization decreased when the pressure was higher than $1.0 \mathrm{MP}_{\mathrm{a}}$

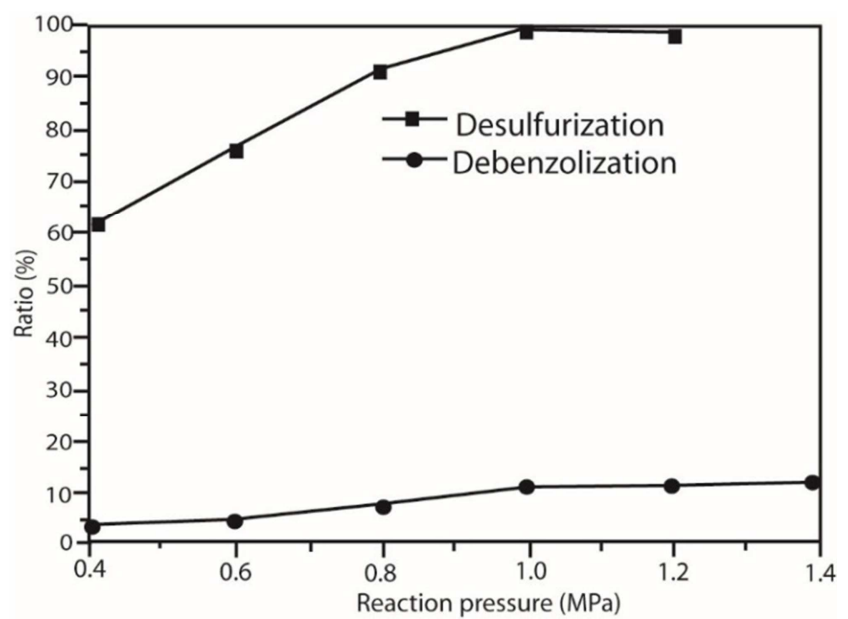

Figure 7. Effect of pressure on desulfurization and debenzolization.

\subsection{Effect of Space Velocity on Desulfurization and Debenzolization}

There is a consistent increase in the desulfurization and debenzolization with the increase in space velocity (Figure 8). The desulfurization and debenzolization reached a maximum of $98 \%$ and $18.9 \%$ respectively, with the space velocity of $3 \mathrm{~h}^{-1}$. The space velocity of $3 \mathrm{~h}^{-1}$ is suitable for the desulfurization and debenzolization over NbFAPSO-5 catalyst. 


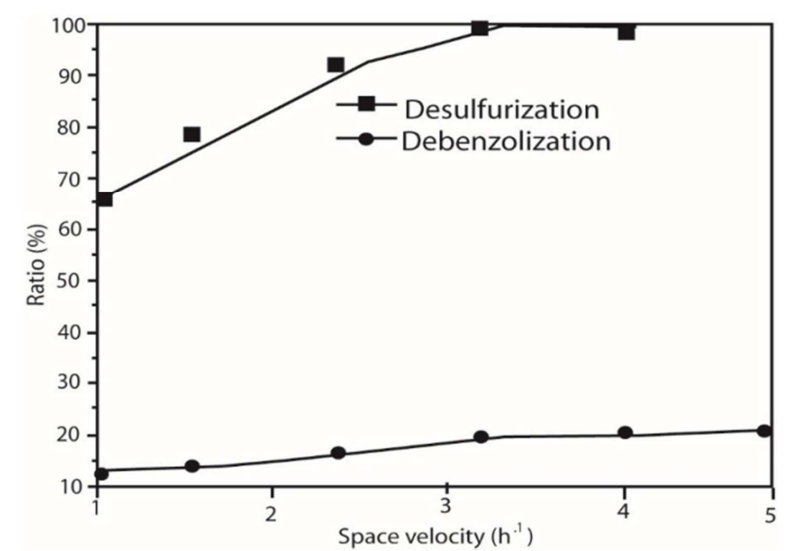

Figure 8. Effect of space velocity on desulfurization and debenzolization.

\subsection{Test of Stability}

The stability of NbFAPSO-5 evaluated for desulfurization and debenzolizationis shown in figure 9.

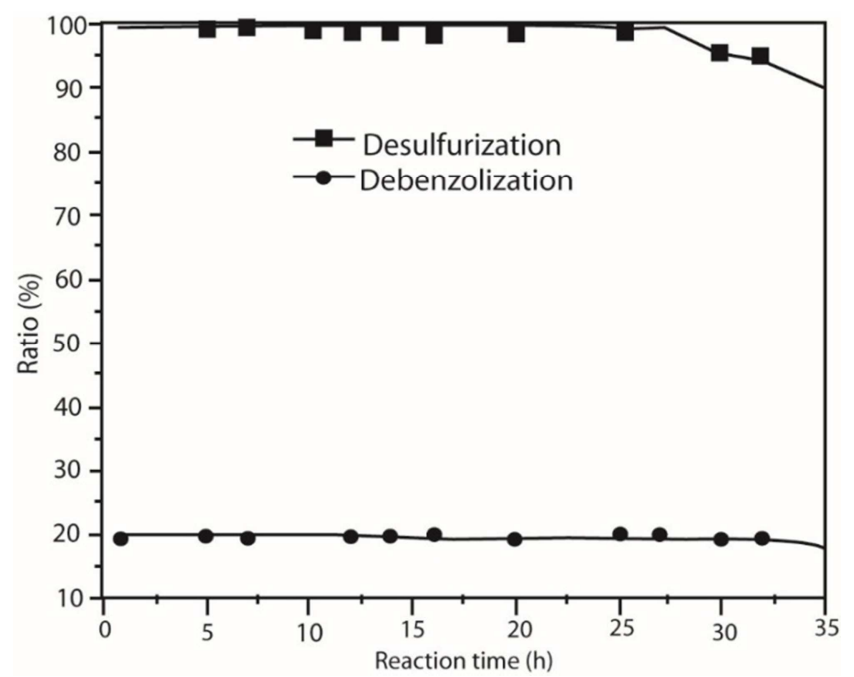

Figure 9. Stability of NbFAPSO-5(a metal loading of 15\%, a reaction temperature of $423 \mathrm{~K}$, a space velocity of $3 h-1$, and reaction pressure of 1 $\mathrm{MPa}$ ).

Desulfurization and debenzolization were almost the same for $25 \mathrm{~h}$ reacting time, showing the steady performance of NbFAPSO-5 catalyst. This behavior could be explained by the stable properties of the catalyst. Deactivation of the catalyst was usually observed in high temperature condition.

\section{Conclusion:}

Niobium containing aluminophosphate with AlPO-5 type structure (NbFAPSO-5) is a prominent active catalyst for desulfurization and debenzolization of gasoline under mild conditions. This catalyst showed good performance in desulfurization and debenzolization of FCC gasoline. Desulfurization and debenzolization ratios reached $99 \%$ and $19.9 \%$, respectively, at the $\mathrm{Nb}$ loading of $15 \%$. Desulfurization and debenzolization increased with increasing pressure, which indicates that pressure has significant effect on desulfurization and debenzolization activity. Desulfurization and debenzolization are dependent on reaction temperature, reaction pressure, metal loading, and reaction time. Although other variables affect these reactions, mild conditions are more favorable for these reactions to proceed. NbFAPSO-5 has high catalytic activities and stability for a reacting period of 25 hours.

\section{References}

[1] Lee, K. X, Valla, J. A. (2017). Investigation of metalexchanged mesoporous $Y$ zeolites for the adsorptive desulfurization of liquid fuels. Appl. Catal. B-Environ, 201. 359-369.

[2] Timko M. T., J. Wang, J. Burgess, (2016). Roles of surface chemistry and structural defects of activated carbons in the oxidative desulfurization of benzothiophenes, Fuel. 163223 231.

[3] Song C. S., X. L. Ma, (2004). Ultra-deep desulfurization of liquid hydrocarbon fuels: chemistry and process, Int. J. Green Energy 1.167-191.

[4] Aziz F., M. Remi, S. Abdullah, T. Ihsan, A. Gasan,(2016). Pervaporative desulfurization of gasoline: a review, Chem. Eng. Process. 107.94-105.

[5] Dokjampa S., Rirksomboon T., Phuong D., D. E. Resasco. (2007). Ring opening of 1, 3-dimethylcyclohexane on Ir catalysts: modification of product distribution by addition of $\mathrm{Ni}$ and $\mathrm{K}$ to improve fuel properties, J. Mol. Catal. A: Chem. 274.231-240.

[6] Santikunaporn M., Alvarez W. E., Resasco D. E. (2007). Ring contraction and selective ring opening of naphthenic molecules for octane number improvement, Appl. Catal. A: Gen. 325. 175-187.

[7] Santana R. C., Do P. T., Santikunaporn M., Alvarez J. D., Taylor, Sughrue. (2006). Evaluation of different reaction strategies for the improvement of cetane number in diesel fuels, Fuel 85. 643-656.

[8] Zepeda T. A., Pawelec B., León J., Reyes J., Olivas A.(2012). Effect of gallium loading on the hydrodesulphurization activity of unsupported Ga2S3/WS2catalysts, Appl. Catal. B: Environ. 112.10-19.

[9] Song H. Y., Gao J. J., Chen X. Y., He J., Li C. H. X. (2013). Catalytic oxidation- extractive desulfurization for model oil using inorganic salts as oxidant and Lewis acid-organic acid mixture as catalyst and extractant, Appl. Catal. A-Gen. 456.67-74.

[10] Sudhakar M., Vijay Kumar V., Naresh G., Lakshmi Kantam M., Bhargava S. K., Venugopal A., (2016). Vapor phase hydrogenation of aqueous levulinic acid over hydroxyapatite supported metal ( $\mathrm{M}=\mathrm{Pd}, \mathrm{PtRu}, \mathrm{Cu}, \mathrm{Ni})$ catalysts, Appl. Catal. BEnviron. 180.113-120.

[11] Kumar S. A. K., John M., Pai S. M., Niwate Y., Newalkar B. L., (2014). Low temperature hydrogenation of aromatics over PtPd/SiO2-Al2O3catalyst, Fuel Process. Technol. 128.303-309.

[12] Bianchini C., Santo V. D., Meli A., Moneti S., Moreno M., Oberhauser W.(2003). A comparison between silica-immobilized ruthenium (II) single sites and silica-supported ruthenium nanoparticles in the catalytic hydrogenation of model hetero- and polyaromatics contained in raw oil materials, J. Catal. 213.47-62. 
[13] Ringelhan C., Burgfels G., Neumayr J. G., Seuffert W., Klose J., Kurth V.(2004). Conversion of naphthenes to a high value steam cracker feedstock using H-ZSM-5 based catalysts in the second step of the ARINO ${ }^{\circledR}$-process, Catal. Today 97.277282.

[14] Raichle A., Traa Y., Fuder F., Rupp M., Weitkamp J., (2001). Haag-Dessau catalysts for ring opening of cycloalkanes, Angew. Chem. Int. Ed. 40.1243-1246.

[15] Wang J., Yao Q. Li, J., (1999). The effect of metal-acid balance in Pt-loading dealuminated Y zeolite catalysts on the hydrogenation of benzene, Appl. Catal. A: Gen. 184 181-188.

[16] Weitkamp J., Raichle A., Traa Y., Rupp M., Fuder F.(2000). Preparation of synthetic steam cracker feed from cycloalkanes (or aromatics) on zeolite catalysts, Chem. Commun. 5.403404.

[17] Mévellec V., Roucoux A., Ramirez E., Philippot K., Chaudret B. (2004). Surfactant-stabilized aqueous iridium (0) colloidal suspension: an efficient reusable catalyst for hydrogenation of arenes in biphasic media, Adv. Synth. Catal. 346 72-76.

[18] Julião D., Gomes A. C., Pillinger M., Luís C.-S., Castro. Balula S. S. (2015). Desulfurization of model diesel by extraction/oxidation using a zinc-substituted polyoxometalate as catalyst under homogeneous and heterogeneous (MIL-
101(Cr) Encapsulated) conditions. Fuel Process. Technol. 131. $78-82$.

[19] Gupta M., He J., Nguyen T., Petzold F., Fonseca D., Jasinski J. B., Sunkara M. K.(2016) Nanowire catalysts for ultra-deep hydrodesulphurization and aromatic hydrogenation, Appl. Catal. B-Environ. 180 246-254.

[20] Mévellec V., Roucoux A., Ramirez E., Philippot K., Chaudret B. (2004). Surfactant-stabilized aqueous iridium (0) colloidal suspension: an efficient reusable catalyst for hydrogenation of arenes in biphasic media, Adv. Synth. Catal. 346 72-76.

[21] Gonzales and Delacruz,(1999). Computational Study of Substitution of $\mathrm{Al}$ by $\mathrm{Fe} 3+$ in the AlPO-5 Framework. Microporous and Mesoporous Materials, 29. 361-365.

[22] Wilson, Flanigen and Pfaff,(1982). Crystalline Metallophosphate Composition. USP 4310440.

[23] Lei Wang, Qian Liu, Chunyu Jing c, Jiajia Yina, Nchare Mominou, Shuzhen Li (2018). Simultaneous removal of sulfides and benzene in FCC gasoline by in situ hydrogenation over NiLaIn/ZrO2-r- $\mathrm{Al}_{2} \mathrm{O}_{3}$. Journal of Hazardous Materials342.758-769. 